\title{
Proteome of germinating and dormant axillary buds of sugarcane and analysis of sprouting- related proteins
}

Mariana Mancini Benez ${ }^{1}$, Rone Charles Maranho ${ }^{1}$, Gustavo Barizon Maranho ${ }^{1}$, Adeline Neiverth ${ }^{2}$, Marise Fonseca dos Santos ${ }^{2}$, Ana Lúcia de Oliveira Carvalho ${ }^{3}$, Adriana Gonela ${ }^{4}$, Claudete Aparecida Mangolin ${ }^{5}$, Maria de Fátima Pires da Silva Machado ${ }^{5^{*}}$

\author{
${ }^{1}$ Postgraduate program in Agronomy, Universidade Estadual de Maringá, Maringá PR Brazil \\ ${ }^{2}$ Department of Biosciences, Universidade Federal do Paraná, Palotina PR Brazil \\ ${ }^{3}$ Institute of Medical Biochemistry, Proteomic Mass Spectrometry Unit, Universidade Federal do Rio de Janeiro, Rio \\ de Janeiro RJ Brazil \\ ${ }^{4}$ Department of Agronomy, Universidade Estadual de Maringá, Maringá PR Brazil \\ ${ }^{5}$ Department of Biotechnology, Genetics and Cell Biology, Universidade Estadual de Maringá, Maringá PR Brazil
}

\author{
*Corresponding author: mfpsmachado@uem.br
}

\begin{abstract}
The germination potential of the axillary buds is crucial for the installation of new sugarcane crop and is highly relevant for the maintenance of the crop during the regrowth cycles. In this way, 1-DE-UPLC-ESI-Q-TOF system of mass spectrometry in a shotgun approach evaluated total and differential proteome of germinating and dormant axillary buds of cultivar RB867515 in second ratoon. The current paper investigates whether differently expressed proteins can be detected in germinating axillary buds or not. The proteome of germinative and dormant axillary buds were obtained using TCA/acetone in triplicates with subsequent proteins and polypeptides pre-separation by SDS-PAGE and UPLC. Mass spectra were obtained via MS/MS and were confronted with Viridiplante mass spectra from NCBIprot, SwissProt and UniProtKB databases, using Mascot tool from Matrix Science. A total of 159 proteins were identified. In total, 46 proteins were exclusively detected in the germinating buds, while 41 proteins were exclusively reported in the dormant buds and 72 proteins were common in germinating and dormant buds. Different proteins, involved with biotic and abiotic stress, were detected at equivalent proportions in germinating (29.5\%) and dormant (31.7\%) buds, while contrasting proportions of proteins involved with energy metabolism were detected in germinating $(22.7 \%)$ and dormant (12\%) buds. Budding potential in the third cut seems to be determined by specific proteins related to energy metabolism and steps of the biosynthesis of primary and secondary metabolites for shoot growth and development. Seven enzymes (Aconitase, Succinate dehydrogenase, Pyruvate dehydrogenase, Fructose-6-phosphate 1-phosphotransgerase, Chacone synthase, Chalcone isomerase, and Monodehydroascorbate), one protein subunits (RuBisCo large subunit-binding protein) and one protein of Argonaute protein family (Tudor-Sn) supposedly involved with germinating potential of axillary buds and two enzymes (Hexokinase and Aldehyde dehydrogenase) supposedly involved with non-budding were highlighted.
\end{abstract}

Keywords: Saccharum spp., sprouting, second ratoon, mass spectrometry, budding potential.

Abbreviations: UPLC-ESI-Q-TOF_Ultra Performance Liquid Chromatography-Electrospray lonization-Quadrupole-Time Of-Flight.

Introduction

Biomass production is one of the most important attributes of sugarcane (Saccharum spp.; Poaceae) crops. Among the fibrous plants, sugarcane (highlighting energy cane) has one of the significant potential for biomass productions (Carvalho-Netto et al., 2014). Sugarcane biomass is the source of raw material for obtaining sugar, first and second generation ethanol, and electric energy co-generation (Pereira et al., 2015). Sugarcane propagation in commercial systems depends on the budding of axillary buds in the stalks (Ming et al., 2006) and higher biomass production is dependent on the germinating potential of axillary buds (budding of the axillary buds) and regrowth of axillary buds remaining in the field after successive harvests. The germination potential of the axillary buds is crucial for the installation of new sugarcane crop. Likewise, the regrowth of axillary buds is highly relevant for the maintenance of the crop during the regrowth cycles (Ongaro et al., 2008; OrtizMorea et al., 2013).

Several factors may influence the budding of axillary buds in sugarcane plants. Climatic factors (temperature and humidity), genetic and physiological factors (variety, age, size and others), cultural practices (Crusciol et al., 2010), and apical dominance inducing meristems to develop into new shoots (Leyser, 2009) may influence the budding of the 
axillary buds. The transcriptome analysis in germinating and dormant axillary buds of sugarcane revealed that a microRNA of interference (miRNA 159) blocks the physiological response of gibberellic acid in stimulating cellular proliferation (Ortiz-Morea et al., 2013). The miRNA 159 is modulated by abscisic acid ( $A B A)$. When sugarcane is cut at harvest, the concentration of ABA decreases, miRNA activity is reduced, and the budding of axillary buds occurs. Another 25 families of miRNA plus some small interfering RNA (siRNA) were also identified in axillary buds of sugarcane.

The proteome analysis of germinating axillary buds revealed that proteome of axillary buds is changed at successive cuts in sugarcane culture (unpublished results). A reduction in the number of proteins was evident in the axillary buds of the fifth cut and proteins exclusively detected in the axillary buds of the first and fifth cuts were related. However, the protein pattern of dormant (non-germinating) axillary buds has yet to be elucidated.

The UPLC-ESI-Q-TOF system has been shown to be efficient in the proteome study of several biological materials, including sugarcane (Pacheco et al., 2013; Barnabas et al., 2015) and just as other LC-MS/MS systems present high accuracy, resolution and sensitivity (Ramalingam et al., 2015). UPLC is a chromatographic separation technique similar to HPLC, except for the decreased run time and less use of solvent. Separation on UPLC is performed under high pressure using small particle packed columns $(5 \mu \mathrm{m})$ that improves separation efficiency (Tuli and Ressom, 2009). In addition, pre-fractionation by one-dimensional denaturing polyacrylamide gel electrophoresis (1-DE SDS-PAGE) make the proteomic analysis more efficient, with the identification of higher number of proteins contained in a initial complex mixture, confirming the robustness of these procedures (Lery et al., 2008; Gupta et al., 2016), making the 1-DE shotgun proteomic approaches a good choice for use in sugarcane research. In current study, 1-DE-UPLC-ESI-Q-TOF system of mass spectrometry in a shotgun approach evaluated total and differential proteome of germinating and dormant axillary buds of the cultivar RB867515. The study investigates whether differently expressed proteins can be detected in the germinating axillary buds or not. In this study, proteins that supposedly involved in the germinating potential of axillary buds were also highlighted.

\section{Results}

\section{Protein extraction of axillary buds and protein profile by SDS-PAGE}

The extraction of total proteins following method described by Maranho et al. (2017) provided an average amount of $1.526 \mu \mathrm{g} \cdot \mathrm{mL}^{-1}$ and $1.237 \mu \mathrm{g} \cdot \mathrm{mL}^{-1}$ proteins in the germinating and dormant axillary buds, respectively. Protein pattern obtained by 1DE SDS-PAGE revealed proteins with molecular weights varying between 120 and $10 \mathrm{kDa}$. However, data obtained by mass spectrometry indicated a greater number of proteins than those visualized on the 1DE SDS-PAGE. Regions 1, 4, 8 and 10 on the 1DE SDS-PAGE (Figure 1) had their proteins identified by mass spectrometry, but they were not identified in 1DE SDS-PAGE electrophoresis.

\section{Identification of germinative and dormant axillary bud proteins}

A total of 159 proteins (Figure 2) were identified in the axillary buds of cultivar RB867515 in the second ratoon. 118 proteins were detected in the germinating buds and 113 proteins in the dormant buds. Seventy two proteins were common in germinating and dormant buds, whereas 46 and 41 proteins were differently expressed in germinating and dormant buds, respectively (see Supplementary Tables S1 and S2). Germinating buds showed only 5 proteins more than dormant buds.

The different proteins identified in the germinating and dormant buds of cultivar RB867515 are related with several biological processes (some can be seen in Tables 1 and 2), such as energy metabolism; growth and cellular development; biogenesis of ribonucleoproteins and elongation factors; biosynthesis of proteins and fatty acids; amino acids metabolism; folding and targeting of proteins; biosynthetic pathway of secondary metabolites; synthesis and processing of RNA, and different proteins as a response to biotic and abiotic stress. Different proteins involved in response to biotic and abiotic stress were detected at equivalent proportions in germinating $(29.5 \%)$ and dormant (31.7\%) buds, while a remarkably greater proportion of proteins involved in energy metabolism were registered in the germinating buds. A contrasting proportion of proteins involved in energy metabolism were detected in the germinating (22.7\%) and dormant (12\%) buds.

\section{PPI analysis of differential proteins identified in germinative and dormant axillary buds}

In order to verify the relationship between proteins differently identified in each type of axillary bud, the 46 and 41 proteins detected in germinative and dormant axillary buds, respectively, were blasted against the Zea mays and Arabidopsis thaliana protein database. Figures 3 and 4 have shown the protein interactions network corresponding to differential proteins of germinative and dormant axillary buds, respectively, indicating that most proteins are biologically connected as a group in both cases. Some proteins detected in sugarcane do not appear in the databases used in STING 10.5. The protein interaction network of germinative axillary buds showed 29 nodes, 42 edges, an average of 2.9 nodes and expected number of edges equal to 14 , while the protein interaction network of the dormant axillary buds showed 37 nodes, 53 edges, an average of 2.86 nodes and expected number of edges equal to 21. Tables 1 and 2 show the biological processes, molecular functions and KEGG pathways obtained by the STRING 10.5 tool for some proteins differently identified in germinative and dormant buds.

\section{Discussion}

Among the various proteins involved in energy metabolism in the germinating buds of cultivar RB867515, the aconitase (ACO; EC 4.2.1.3) is an enzyme in the mitochondrial matrix that catalyzes the stereo specific isomerization of citrate to isocitrate via cis-aconitate in the tricarboxylic acid cycle (TAC); the second reaction sequence in the TCA cycle requires ACO. Absence or deficit of ACO produces a 
Table 1. Functional network enrichment by String v.10.5 for differential proteome of germinative axillary buds.

\begin{tabular}{|c|c|c|c|}
\hline \multicolumn{4}{|c|}{ Biological Process (GO) } \\
\hline Pathway ID & Pathway description & Count in gene set & $\begin{array}{l}\text { False discovery } \\
\text { rate }\end{array}$ \\
\hline GO:0046686 & Response to cadmium ion & 10 & $6.16 \mathrm{e}-09$ \\
\hline GO:0044710 & Single-organism metabolic process & 22 & $1.77 \mathrm{e}-08$ \\
\hline GO:0010035 & Response to inorganic substance & 11 & $7.95 e-07$ \\
\hline GO:0044281 & Small molecule metabolic process & 14 & $8.03 e-07$ \\
\hline GO:0044699 & Single-organism process & 25 & $2.56 \mathrm{e}-05$ \\
\hline GO:0055114 & Oxidation-reduction process & 12 & $2.56 \mathrm{e}-05$ \\
\hline GO:1901564 & $\begin{array}{l}\text { Organonitrogen compound metabolic } \\
\text { process }\end{array}$ & 12 & $2.56 \mathrm{e}-05$ \\
\hline GO:0043436 & Oxoacid metabolic process & 10 & 0.000146 \\
\hline GO:0019752 & Carboxylic acid metabolic process & 9 & 0.000749 \\
\hline GO:0042221 & Response to chemical & 13 & 0.0011 \\
\hline GO:0050896 & Response to stimulus & 17 & 0.00259 \\
\hline GO:0006520 & Cellular amino acid metabolic process & 6 & 0.00303 \\
\hline GO:0010255 & Glucose mediated signaling pathway & 2 & 0.00342 \\
\hline GO:0044237 & Cellular metabolic process & 21 & 0.00687 \\
\hline GO:1901605 & Alpha-amino acid metabolic process & 5 & 0.00897 \\
\hline GO:0008152 & Metabolic process & 23 & 0.013 \\
\hline GO:0009628 & Response to abiotic stimulus & 9 & 0.0138 \\
\hline GO:0071333 & Cellular response to glucose stimulus & 2 & 0.0182 \\
\hline GO:0006575 & $\begin{array}{l}\text { Cellular modified amino acid metabolic } \\
\text { process }\end{array}$ & 3 & 0.0299 \\
\hline GO:0009651 & Response to salt stress & 5 & 0.0306 \\
\hline GO:0071704 & Organic substance metabolic process & 20 & 0.033 \\
\hline GO:0006950 & Response to stress & 11 & 0.0344 \\
\hline GO:0006544 & Glycine metabolic process & 2 & 0.036 \\
\hline GO:0006732 & Coenzyme metabolic process & 4 & 0.036 \\
\hline GO:0019725 & Cellular homeostasis & 4 & 0.036 \\
\hline GO:0006749 & Glutathione metabolic process & 2 & 0.038 \\
\hline GO:0006790 & Sulfur compound metabolic process & 4 & 0.0391 \\
\hline GO:0042742 & Defense response to bacterium & 4 & 0.0418 \\
\hline
\end{tabular}

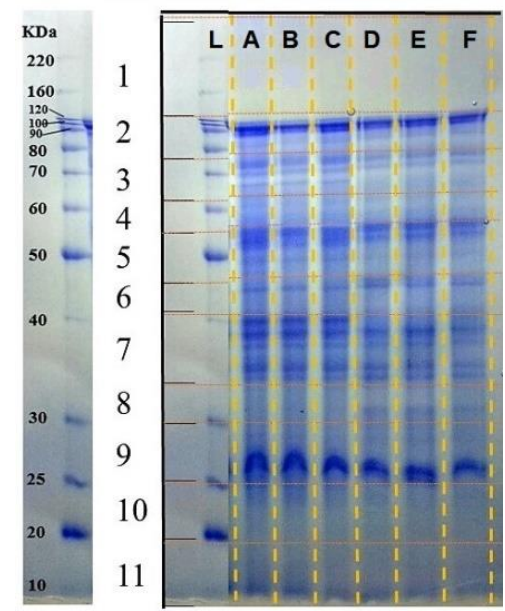

Fig 1. 1-DE SDS-PAGE with the sugarcane protein profile from active axillary buds $(A, B, C)$ and dormant axillary buds $(D, E, F)$. The cut lines are markings for the preparation and MS analyses. 1-11: Gel cutting regions; L: Ladder. 
Table 2. Functional network enrichment by String v.10.5 for differential proteome of dormant axillary buds.

\begin{tabular}{|c|c|c|c|}
\hline \multicolumn{4}{|c|}{ Biological Process (GO) } \\
\hline Pathway ID & Pathway description & Count in gene set & False discovery rat \\
\hline GO:0046686 & Response to cadmium ion & 10 & $6.16 \mathrm{e}-09$ \\
\hline GO:0044710 & Single-organism metabolic process & 22 & $1.77 e-08$ \\
\hline GO:0010035 & Response to inorganic substance & 11 & $7.95 e-07$ \\
\hline GO:0044281 & Small molecule metabolic process & 14 & $8.03 e-07$ \\
\hline GO:0044699 & Single-organism process & 25 & $2.56 \mathrm{e}-05$ \\
\hline GO:0055114 & Oxidation-reduction process & 12 & $2.56 e-05$ \\
\hline GO:1901564 & Organonitrogen compound metabolic process & 12 & $2.56 e-05$ \\
\hline GO:0043436 & Oxoacid metabolic process & 10 & 0.000146 \\
\hline GO:0019752 & Carboxylic acid metabolic process & 9 & 0.000749 \\
\hline GO:0042221 & Response to chemical & 13 & 0.0011 \\
\hline GO:0050896 & Response to stimulus & 17 & 0.00259 \\
\hline GO:0006520 & Cellular amino acid metabolic process & 6 & 0.00303 \\
\hline GO:0010255 & Glucose mediated signaling pathway & 2 & 0.00342 \\
\hline GO:0044237 & Cellular metabolic process & 21 & 0.00687 \\
\hline GO:1901605 & Alpha-amino acid metabolic process & 5 & 0.00897 \\
\hline GO:0008152 & Metabolic process & 23 & 0.013 \\
\hline GO:0009628 & Response to abiotic stimulus & 9 & 0.0138 \\
\hline GO:0071333 & Cellular response to glucose stimulus & 2 & 0.0182 \\
\hline GO:0006575 & Cellular modified amino acid metabolic process & 3 & 0.0299 \\
\hline GO:0009651 & Response to salt stress & 5 & 0.0306 \\
\hline GO:0071704 & Organic substance metabolic process & 20 & 0.033 \\
\hline GO:0006950 & Response to stress & 11 & 0.0344 \\
\hline GO:0006544 & Glycine metabolic process & 2 & 0.036 \\
\hline GO:0006732 & Coenzyme metabolic process & 4 & 0.036 \\
\hline GO:0019725 & Cellular homeostasis & 4 & 0.036 \\
\hline GO:0006749 & Glutathione metabolic process & 2 & 0.038 \\
\hline GO:0006790 & Sulfur compound metabolic process & 4 & 0.0391 \\
\hline GO:0042742 & Defense response to bacterium & 4 & 0.0418 \\
\hline \multicolumn{4}{|c|}{ Molecular Function (GO) } \\
\hline Pathway ID & Pathway description & Count in gene set & False discovery rate \\
\hline GO:0016491 & Oxireductase activity & 12 & $1.97 e-05$ \\
\hline GO:0043168 & Anion binding & 16 & $1.97 e-05$ \\
\hline GO:0003824 & Catalytic activity & 23 & $3.24 \mathrm{e}-05$ \\
\hline GO:0048037 & Cofator binding & 8 & $3.24 \mathrm{e}-05$ \\
\hline GO:0036094 & Small molecule binding & 14 & 0.000616 \\
\hline GO:0000166 & Nucleotide binding & 13 & 0.0016 \\
\hline GO:0043167 & lon binding & 18 & 0.0016 \\
\hline GO:0050662 & Coenzime binding & 5 & 0.00651 \\
\hline GO:0097159 & Organic cyclic compound binding & 17 & 0.00651 \\
\hline GO:1901363 & Heterocyclic compound binding & 17 & 0.00651 \\
\hline GO:0005507 & Copper ion binding & 4 & 0.00882 \\
\hline GO:0097367 & Carbohydrate derivative binding & 10 & 0.0418 \\
\hline GO:0016881 & Acid-amino ligase activity & 2 & 0.0427 \\
\hline \multicolumn{4}{|c|}{ KEGG Pathways } \\
\hline Pathway ID & Pathway description & Count in gene set & False discovery rate \\
\hline 01120 & Microbial metabolism in diverse environments & 9 & $1.28 \mathrm{e}-07$ \\
\hline 01100 & Metabolic pathways & 12 & 0.000152 \\
\hline 00480 & Glutathione metabolism & 4 & 0.000323 \\
\hline 00260 & Glycine, serine and threonine metabolism & 3 & 0.00344 \\
\hline 01110 & Biosynthesis of secondary metabolites & 7 & 0.00564 \\
\hline 01200 & Carbon metabolism & 4 & 0.00564 \\
\hline 00670 & One carbon pool by folate & 2 & 0.00611 \\
\hline 00020 & Citrate cycle (TCA cycle) & 2 & 0.0435 \\
\hline 00903 & Limonene and pinene degradation & 2 & 0.0471 \\
\hline
\end{tabular}




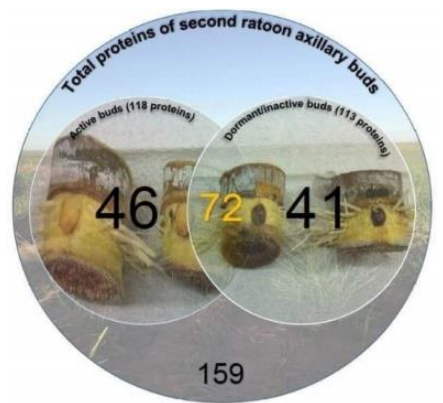

Fig 2. Total and differential proteins of the axillary buds of sugarcane RB 867515 cultivar: 72 proteins were common in active and dormant/inactive buds, whereas 46 and 41 proteins were differently expressed in germinating and dormant buds.

Table 3. Experimental conditions used for separation of peptides by reverse-phase chromatography.

\section{Solutions}

Solution A

Solution B

Solution C

Chromatographic columns

Pre column - Symmetry C18 $180 \mu \mathrm{m} \times 20 \mathrm{~mm}, 5 \mu \mathrm{m}$

Analytical column - BEH $130 \mathrm{C} 18100 \mu \mathrm{m} \times 100$ mm, $1.7 \mu \mathrm{m}$

Chromatographic gradients

Trapping -15 minutes of $97 \%$ of solution A at a flow rate of $10 \mu \mathrm{L} / \mathrm{min}$

Chromatographic gradients - Elute peptides not retained by solution B in the range of $3 \%$ to $50 \%$ with a $1.5 \%$

increase of solution $B$ per column volume, at a flow rate of $0.5 \mu \mathrm{L} / \mathrm{min}$

Reference

Solution $\mathrm{C}$ at $0.35 \underline{\mu \mathrm{L} / \mathrm{min}}$
$99.9 \%$ water $+0.1 \%$ formic acid

$99.9 \%$ acetonitrile $+0,1 \%$ formic acid

GFP $320 \mathrm{fmol} / \mathrm{uL}$ in $50 \%$ acetonitrile $+50 \%$ water

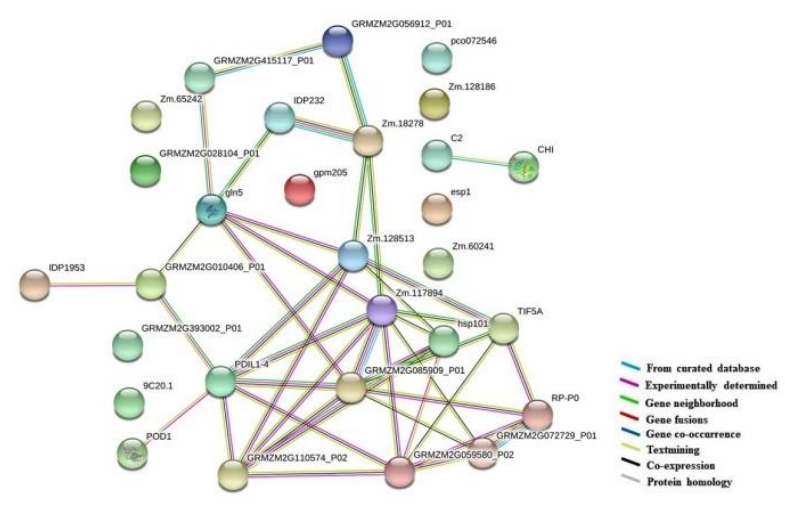

Fig 3. Analysis of protein interaction network by STRING 10.5. Zea mays homologous proteins from differentially identified proteins in germinative axillary buds were mapped by searching the STRING 10.5 tool with the confidence setting in a level of 0.400 . The line that bind proteins (nodes) indicate the diverse types of interaction evidence.

Table 4. Parameters used to identify proteins by Mascot in axillary buds of sugarcane RB867515 cultivar.

\section{Parameter:}

Enzyme

Missed clevages

Taxonomy

Databases

Fixed modifications

Variable modifications

Peptide tolerance

MS/MS tolerance

Peptide charge
Trypsin

1

Green Plants (Viridiplantae)

NCBIprot; SwissProt; UniProtKB

Carbamidomethyl (C) - Carbamethylation of cysteine

Oxidation (M) - Oxidation of metionine

50 PPM

$0.3 \mathrm{Da}$

$1+, 2+$ and $3+$ 

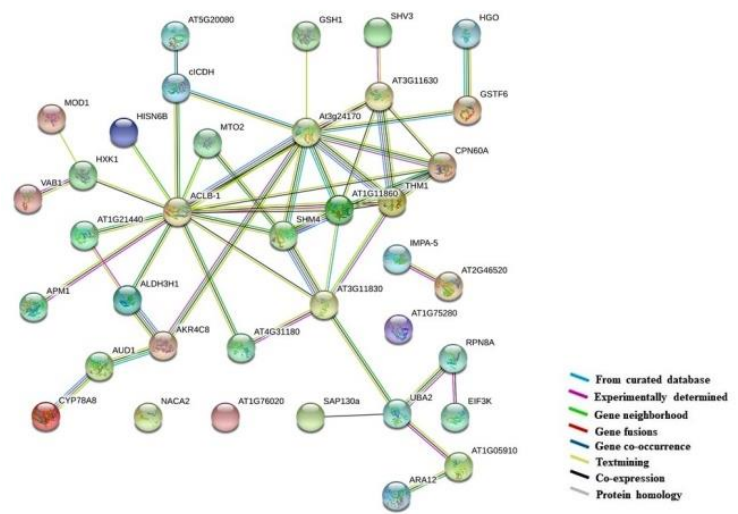

Fig 4. Analysis of protein interaction network by STRING 10.5. Arabidopsis thaliana homologous proteins from differentially identified proteins in dormant axillary buds were mapped by searching the STRING 10.5 tool with the confidence setting in a level of 0.400 . The line that bind proteins (nodes) indicate the diverse types of interaction evidence.

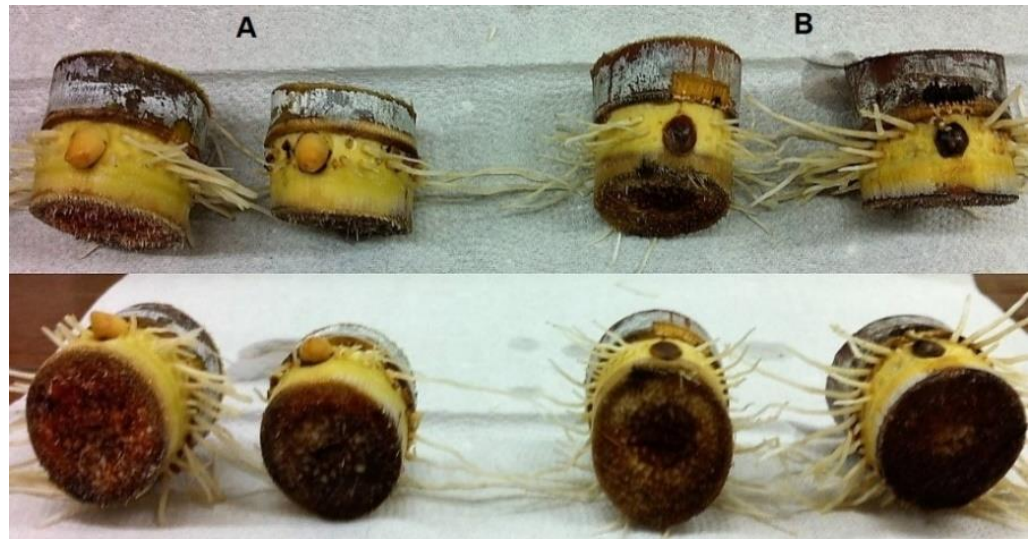

Fig 5. Axillary buds of the cultivar RB867515 which were classified as germinative (A) and dormant (B).

respiratory-deficient phenotype in Arabidopsis thaliana (Mcalister-Henn and Small, 1997).

Succinate dehydrogenase (SDH; EC 1.3.99.1 and complex II, EC 1.3.5.1) also has a central role in mitochondrial metabolism. In fact, it is the only component enzyme in the TCA cycle and in the electron transport chain. SDH catalyzes the oxidation of succinate to fumarate in the mitochondria matrix and transfers electrons to ubiquinone without pumping protons across the mitochondrial inner membrane. Loss or mutation of SDH subunits in plants decreases SDH activity and respiration rate (Huang and Millar, 2013).

The pyruvate dehydrogenase complex (PDH; EC 1.2.4.1) is found both in the mitochondrial and proplastid fractions in the tissue. PDH catalyzes the oxidative decarboxylation of pyruvate with the formation of acetyl-CoA and the reduction of $\mathrm{NAD}^{+}$(Tovar-Méndez et al., 2013). Since acetyl-CoA may be used in the TCA cycle to carry out cellular respiration, pyruvate dehydrogenase contributes towards linking glycolysis metabolic pathway to the TCA cycle and releasing energy via NADH.

Fructose-6-phosphate 1-phosphotransferase (PFP; EC 2.7.1.90) in cytosol catalyzes reversible interconversion between fructose-6-phosphate and fructose-1,6bisphosphate, a rate-limiting step in the regulation of the primary carbohydrate metabolic flux toward glycolysis or gluconeogenesis (Basson et al., 2011). PFP utilizes pyrophosphate (PPi) as an alternative phosphoryl donor in place of ATP during the phosphorylation of Fru-6-P to Fru1,6-P2. The latter provides energy advantage to plants (Lim et al., 2009).

RuBisCO large subunit-binding protein (RBP) detected in the germinating buds, but not in the dormant buds, is involved in the assembly of the Ribulose-1,5-bisphosphate carboxylase/oxygenase activase (RCA; EC 4.1.1.39), a chloroplast enzyme that plays an important role in photosynthesis. Depending upon the molecular concentration of $\mathrm{CO}_{2}$ or $\mathrm{O}_{2}$, rubisco is the only enzyme that catalyzes carboxylation or oxygenation reaction. As a carboxylase, Rubisco catalyzes RuBP and $\mathrm{CO}_{2}$ combined resulting in the formation of two 3-PGA molecules (Wang et al., 2012). 3-PGA plus ATP and NADPH coming from photosynthesis may build carbohydrates (hexoses) in subsequent phases of the Calvin cycle (Santos and Diola, 2015). Absence or deficit of RBP implicated in the assembly of the most abundant soluble protein in the chloroplast (Rubisco) may be one of the factors that restrict the development of dormant buds in sugarcane.

The protein Tudor-SN should be highlighted since it is supposedly involved in the germinating potential of axillary buds of the cultivar RB867515. Tudor-SN is an evolutional conserved RNA binding protein (RBP) with several roles at physiological and cellular levels (Chou et al., 2017). Tudor-SN 
has RNA binding activity and interacts with proteins involved in plant growth, transcription and stress response. Its role in regulating several transcriptional and post-transcriptional events has been underscored in various studies, such as transport of mRNA to the Endoplasmic Reticulum (Wang et al., 2008), reproduction and embryogenesis (Sundström et al., 2009), seed-germination and flowering (Kuhn et al., 2008; Zhang et al., 2008) and response mechanisms to various types of stress (Frei Dit Frey et al., 2010; GutierrezBeltran et al., 2015). Tudor-SN interacts with stress granule (SG) proteins (Scadden, 2007) containing mRNA accumulated by translation inhibition, initiation complexes and small ribosomal proteins, which provide a means of survival during stress (Kedersha et al., 2002; Anderson and Kedersha, 2009; Weissbach and Scadden, 2012). Tudor-SN may also have a prominent role in secretion (Chou et al., 2017). The Tudor-SN protein also acts on plant hormone biosynthesis (Yan et al., 2014). Ortiz-Morea et al. (2013) studied the role of small RNAs in dormant and germinating axillary buds of sugarcane and revealed that specific miRNAs were differentially expressed in developing buds. Some miRNAs were correlated negatively with the expression of their targets at specific stages of axillary bud development. The expression patterns of miR159 suggested that they may play roles in regulating abscisic acid-signaling pathways during sugarcane bud outgrowth.

The chalcone synthase (CHS; EC 2.3.1.74) was only detected in the germinating buds of the cultivar RB867515, which involved in regulating hormonal pathways in $A$. thaliana. Brown et al. (2001) observed that CHS deficiency induces phenotypic effects characteristic of auxin transport inhibitors, such as growth and development inhibition. CHS is a key enzyme in the biosynthetic pathway of flavonoids in response to reactive oxygen species (Agati et al., 2007; Fini et al., 2011; ), UV light (Hahlbrock and Scheel, 1989; Li et al., 1993; Dao et al., 2011), drought stress (Lijuan et al., 2015), and in response to phytopathogens, such as viruses, bacteria, fungi, nematodes and other pests attacking plants, and elicitors wounding different parts of the plant (Richard et al., 2000; Ellis and Turner, 2002). Review by Dao et al. (2011) has described CHS and its function in plant resistance. The chalcone isomerase ( $\mathrm{CHI}$; EC 5.5.1.6), also known as flavanone lyase or chalcone-flavanone isomerase, is also an enzyme involved in the biosynthetic pathway of flavonoids. $\mathrm{CHI}$ catalyzes the intramolecular cyclization of bicyclic chalcones into tricyclic (S)-flavanones (Jez and Noel, 2002). The activity of $\mathrm{CHI}$ is essential for the biosynthesis of flavanone precursors of floral pigments and phenylpropanoid plant defense compounds. Plants use flavonoids as floral pigments for attracting pollinators, as inducers of Rhizobium nodulation genes, anti-microbial phytoalexins and for protection against damaging UV light. Monodehydroascorbate reductase (MDAR; EC 1.6.5.4) is another protein involved in plant defense detected in germinating buds of cultivar RB867515. MDAR is an enzyme that catalyzes the conversion of monodehydroascorbate in ascorbate $\left[\mathrm{NADH}+\mathrm{H}^{+}+2\right.$ monodehydroascorbate $\rightarrow \mathrm{NAD}^{+}+$ 2 ascorbate]. MDHAR activation in response to various stress conditions has been observed in many plant species (Shin et al., 2013). Ascorbate is a very important antioxidant molecule in plants for the maintenance of ROS scavenging ability. The activity of MDHAR in ascorbate recycling in the ascorbate-glutathione cycle is important in the acquired tolerance of crop plants to abiotic environmental stress.

Approach in current study has been the highlighting of proteins supposedly involved in germination potential of axillary bud, despite the important proteins detected in dormant axillary buds. Proteins involved in energy metabolism and biosynthetic pathway of primary and secondary metabolites for cellular growth and development were also detected in dormant axillary buds, beside proteins in response to biotic and abiotic stress. It may be underscored that hexokinase (HXK; EC 2.7.1.1), an enzyme detected only in the dormant buds, catalyzes the phosphorylation of glucose for glucose-6-phosphate, a first step in glycolysis. Dai et al. (1999) evidenced that plants with increased HXK activity reveal reduced growth. Growth inhibition, reduced sugar levels in leaves, and decreased yield were attributed to the inhibition of photosynthesis by increased HXK activity. Senescence was also attributed to high HXK activity. HXK activity enzyme decreases photosynthetic genes and hydraulic conductivity (Kelly et al., 2014). There is sufficient evidence that growth inhibition and senescence in dormant axillary buds may be due to high HXK activity levels.

Enzyme aldehyde dehydrogenase (ALD; EC 1.2.1.8) is another protein supposedly involved in non-budding. It is involved in $\mathrm{NAD}^{+}$or $\mathrm{NADP}^{+}$dependent conversion of various aldehydes to their corresponding carboxylic acids. ALD activities seem to be crucial to regulate the accumulation of toxic aldehydes in plants exposed to stress conditions (Sunkar et al., 2003). Aldehydes, generated during the oxidative degradation of lipid membranes (lipid peroxidation), are toxic to cells due to their reactivity and tendency to form high affinity bonds with proteins and DNA (Stiti et al., 2011).

The analysis of the proteome in germinating and dormant axillary buds of the cultivar RB867515 in the third cut confirmed our hypothesis that differently expressed proteins are detected in the germinating axillary buds. More than $50 \%$ of proteins $(54.72 \%)$ identified in the germinating and dormant axillary buds are differently expressed: $28.93 \%$ of the proteins were exclusive of germinating buds, while $25.78 \%$ were identified only in the dormant axillary buds. Therefore, the number of proteins is not determinant on the potential for budding axillary buds, since the proportion of exclusive proteins in germinating buds $(28.93 \%)$ scarcely differs (just $3 \%$ ) from the proportion of exclusive proteins in dormant buds (25.78\%). In sugarcane variety RB867515, the potential for budding in the third cut seems to be determined by specific proteins, identified in the germinating buds, related to energy metabolism and steps of the biosynthesis of primary and secondary metabolites for growth and development of shoots. The budding potential of the axillary buds in the third cut is less than $50 \%$ (precisely $36.4 \%)$. Therefore, it may be determinant on regrowth and productivity decrease of the sugarcane variety in the third cut.

\section{Materials and methods}

\section{Axillary buds from cultivar RB867515}

Axillary buds retrieved from the plants of third stage cuts (second ratoon) of ten-month-old cultivar RB867515 were 
collected from farms of the Nova Aralco Industry, in the state of São Paulo, Brazil. Sugarcane plants, cultivated in a production environment C (Prado, 2008), were collected in close sessions at least 10 meters away from the field's edge. Based on leaf count by the Kuijper system described by Van Dillewijn (1952), only axillary buds from the $4^{\text {th }}$ to the $9^{\text {th }}$ node were used. Axillary buds were selected and planted in vermiculite substrate to initiate sprouting, in tagged 10-liter trays, with a spacing of three centimeters between samples. They were irrigated every two days. Sprouting occurred in a greenhouse after five days at $22^{\circ} \mathrm{C}$, free of biotic and abiotic stresses, with $36.4 \%$ budding.

Based on morphological development, axillary buds were classified as germinating or dormant (Figure 5). Axillary buds (germinating and dormant) were excised by a scalpel aid, instantly frozen in liquid nitrogen, and samples were kept at $-80^{\circ} \mathrm{C}$, until use.

\section{Extraction, quantification and pre-fractioning of total proteins}

Axillary buds (200 mg) were used in triplicates from each germinating and dormant buds. Total proteins were extracted by modified TCA/acetone method for sugarcane axillary buds (Maranho et al., 2017). After extraction, proteins were quantified by a fluorometer (Qubit ${ }^{\circledR}$ Fluorometer 1.0) with Qubit ${ }^{\circledR}$ Protein Assay quantification kit from Life Technologies ${ }^{\mathrm{TM}}$. The extracted proteins were pre-fractionated by 1DE SDS-PAGE, with $12 \%$ visualization gel and 5\% stacking gel. Electrophoresis lasted approximately 3 hours, at 200 volts. Gel was then stained with $0.1 \%$ Comassie Brilliant Blue R-250, photographed and stored in preservative solution, until use.

\section{Sample preparation for MS analyses}

Tryptic digestion was done according to Shevchenko et al. (1996). Each lane of the 1DE SDS-PAGE gel was cut into eleven fragments (Figure 1) by scalpel and negatoscope, previously cleaned with ethanol solution $70 \%$. Gel fragments were divided into proteases-free microtubes, previously washed with methanol. Two fragments were also retrieved, with molecular weight standards $50 \mathrm{kDa}$ and $20 \mathrm{kDa}$, as positive control, and two fragments, without proteins, polypeptides and dyes, as negative control. Comassie Brilliant Blue R-250 dye and sodium dodecyl sulfate (SDS) were removed by washing in acetonitrile solution $50 \%$ in ammonium bicarbonate $\left(\mathrm{NH}_{4} \mathrm{HCO}_{3}\right)$.

Disulfide bonds were reduced by incubation in dithiothreitol (DTT) solution (10 mM DTT and $25 \mathrm{mM} \mathrm{NH}_{4} \mathrm{HCO}_{3}, \mathrm{pH}$ 8.0). Cysteine residues were alkylated by incubation in alkylation solution $(50 \mathrm{mM}$ iodoacetamide in $25 \mathrm{mM}$ ammonium bicarbonate solution). Proteins were digested by trypsin Promega $^{\mathrm{TM}}$ at a final concentration of $0.01 \mu \mathrm{g} \cdot \mu \mathrm{L}^{-1}$, for 16 hours, at $37^{\circ} \mathrm{C}$. Proteins were extracted from the $1 \mathrm{DE}$ gel by extraction solution $(0.1 \%$ formic acid, $50 \%$ acetonitrile, Ultrapure water q.s.p.) and by sonicator for 30 minutes, twice. The extraction solution was removed to microtubes and centrifuged at $2.935 \times \mathrm{g}$ (Sigma-4-16K centrifuge). After centrifugation, samples were dried in a vacuum desiccator until complete dehydration.

\section{UPLC separation and MS analysis}

Samples were re-suspended in $0.1 \%$ formic acid and then desalted by Waters Symmetry ${ }^{\circ} \mathrm{C} 18$ pre-column $(180 \mu \mathrm{m} \times 20$ $\mathrm{mm} ; 5 \mu \mathrm{m})$. The molecules were then applied to the Waters Nano Acquity system UPLC (Waters', Milford, MA); $7.5 \mu \mathrm{L}$ of the sample injection volume was used, separated by liquid chromatography with BEH 130 C18 column (100 $\mu \mathrm{m}$ X 100 $\mathrm{mm}, 1.7 \mu \mathrm{m}$, Waters, Milford, MA) in elution at $0.5 \mathrm{~mL} \cdot \mathrm{min}^{-}$ 1 , linear acetonitrile gradient (10-40\%), containing formic acid $0.1 \%$ (Table 3 ). Sequential mass spectra were obtained with Waters Micromass Q-Tof micro ${ }^{\mathrm{TM}}$ (Waters', Milford, MA) spectrometer, interfacing with NanoAcquity capillary chromatography system.

Electrospray ionization (ESI) was performed at $3500 \mathrm{~V}$, with source temperature at $80^{\circ} \mathrm{C}$ and $30 \mathrm{~V}$ cone voltage. Data acquisition and instrument control were conducted by MassLynx $^{\mathrm{TM}}$ 4.1 (Waters ${ }^{\circ}$ ). Chromatographic runs with amplitude 400-2000 mass/charge ratio $(\mathrm{m} / \mathrm{z})$ were performed with one-second intervals applied throughout the chromatographic process.

Data dependent on MS/MS fragmentation acquisition were performed on the precursors with charges 2, 3 and 4, over a range of $50-2000(\mathrm{~m} / \mathrm{z})$. A maximum of three ions were selected from each spectrum (MS) for further fragmentation by MS/MS. Collision-induced dissociation (CID) was obtained by argon gas at $40 \mathrm{psi}$ and by collision energy, ranging between 18 and 90V, depending on the precursor's charge and mass. Analyses were performed in triplicate.

\section{Data availability}

The raw mass spectrometry proteomics data have been deposited with the ProteomeXchange Consortium via jPOST partner repository with the dataset identifier PXD008008 and JPST000335, respectively.

\section{Bioinformatics}

All data were processed with ProteinLynx Global SERVER ${ }^{\text {TM }}$ 2.5 (Waters) where the mass/charge rate of each precursor (MS) and fragment (MS/MS) was determined by mass spectra from chromatograms with Q-Tof LockSpray ${ }^{\mathrm{TM}}$ system (Waters, Milford, MA) for calibration. Proteins were identified by data processed by ProteinLynx Global SERVER ${ }^{\mathrm{TM}}$, performed by tool from Matrix Science (http://www.matrixscience.com/) and UniProt (http://www.uniprot.org/), with Databases NCBlprot, SwissProt and UniProtKB (available online). Table 4 shows parameters to identify proteins by Mascot. Due to the lack of an open access database for sugarcane proteins, a suitable global open access database was used with Viridiplantae taxonomy.

The proteins that constitute total and differential proteome of the germinating and dormant axillary buds were identified and only proteins with at least one match peptide with a score above the limit indicated by the Mascot were selected, in which ions showed identity or extensive homology $(p<0.05)$. The principle of strict parsimony was adopted. Taking into account the highest score by Mascot, only one protein per identified peptide was considered. A False Discovery Rate (FDR) filter was applied for a maximum of $5 \%$. Further, only proteins and peptides with relative masses 
compatible with the molecular weight of the corresponding region in 1DE SDS-PAGE were taken into account. Mass spectra were matched with contaminant databases available in Mascot, avoiding the use of contaminant peptides in the proteome composition.

The differential proteins of germinative and dormant axillary buds were blasted against the Zea mays and Arabdopsis thaliana protein database, respectively, for protein-protein interaction network (PPI) analysis by STRING 10.5 tool (Szklarczyk et al., 2017). The use of the databases of Zea mays and Arabidopsis thaliana were chosen due to lack of Saccharum proteins database and because they contain more annotations of the biological processes, molecular functions and KEGG Pathways in STRING CONSORTIUM database.

\section{Conclusion}

Budding potential in axillary buds of cultivar RB867515 in the second ratoon is neither related to the number of proteins detected in germinating and dormant buds, nor to the proportion of different proteins induced in response to biotic and abiotic stress. Rather, it is related to differently expressed proteins involved in energy metabolism and steps of the biosynthesis of primary and secondary metabolites needed for the growth and development of shoots.

\section{Acknowledgements}

The authors would like to thank Nova Aralco Industry for the supply of biological material; CAPES (AUXPE-PROEX1799/2015-CAPES-Process N. 23038.004610/2015-45) and CNPq for funding research and granting of scholarships; Unidade de Espectrometria de Massas e Proteômica (UEMP) of the Federal University of Rio de Janeiro (UFRJ) for technical support and proteomic analyses; Federal University of Paraná (UFPR), campus Palotina, for technical support and material for the preparation and treatment of samples.

Conflict of Interest: The authors declare that there is no conflict of interest that could be perceived as prejudicial to the impartiality of the reported research.

\section{References}

Agati G, Matteini P, Goti A, Tattini M (2007) Chloroplastlocated flavonoids can scavenge singlet oxygen. New Phytol. 174: 77-89.

Anderson P, Kedersha N (2009) RNA granules: posttranscriptional and epigenetic modulators of gene expression. Nat Rev Mol Cell Biol. 10: 430-436.

Barnabas L, Ramadass A, Almaraj RS, Palaniyandi M, Rasappa $V$ (2015) Sugarcane proteomics: an update on current status, challenges, and future prospects. Proteomics. 15: 1658-1670.

Basson CE, Groenewald JH, Kossmann J, Cronje C, Bauer R (2011) Upregulation of pyrophosphate: fructose 6phosphate1-phosphotransferase (PFP) activity in strawberry. Transgenic Res. 20: 925-931.

Brown DE, Rashotte AM, Murphy AS, Normaly J, Tague BW, Peer WA, Taiz L, Muday GK (2001) Flavonoids act as negative regulators of auxin transport in vivo in Arabidopsis. Plant Phys. 126: 524-535.
Carvalho-Netto OV, Bressiani JA, Soriano HL, Fiori CS, Santos JM, Barbosa GVS, Xavier MA, Landell MGA, Pereira GAG (2014) The potential of the energy cane as the main biomass crop for the cellulosic industry. Chem Biol Techn Agric. 1: 1-20.

Chou HL, Tian L, Kumamaru T, Hamada S, Okita TW (2017) Multifunctional RNA binding protein OsTudor-SN in storage protein mRNA transport and localization. Plant Phys. 175: 1608-1623.

Crusciol CAC, Silva MA, Rossetto R, Soratto R (2010) Tópicos em Ecofisiologia da cana-de-açúcar. FEPAF, Botucatu, SP, $111 \mathrm{p}$.

Dai N, Schaffer Petreikov AM, Shahak Y, Giller Y, Ratner K, Levine A, Granot D (1999) Overexpression of Arabidopsis hexokinase in tomato plants inhibits growth, reduces photosynthesis, and induces rapid senescence. The Plant Cell. 11: 1253-1266.

Dao TTH, Linthorst HJM, Verpoorte R (2011) Chalcone synthase and its functions in plant resistance. Phytochem Rev. 10: 397-412.

Ellis C, Turner JG (2002) A conditionally fertile coil allele indicates cross-talk between hormone signaling pathways in Arabidopsis thaliana seeds and young seedlings. Planta. 215: 549-556.

Fini A, Brunetti C, Di Ferdinando M, Ferrini F, Tattini $M$ (2011) Stress-induced flavonoids biosynthesis and antioxidant machinery of plants. Plant Signal Behav. 6: 709-711.

Frei Dit Frey N, Muller P, Jammes F, Kizis D, Leung J, Perrotrechenmann C, Bianchi MW (2010) The RNA binding protein Tudor-SN is essential for stress tolerance and stabilizes levels of stress-responsive mRNAs encoding secreted proteins in Arabidopsis. Plant Cell. 22: 15751591.

Gupta R, Lee SJ, Min CW, Kim SW, Park KH, Bae DW, Lee BW, Agrawal GK, Rakwal R, Kim ST (2016) Coupling of gel-based 2-DE and 1-DE shotgun proteomics approaches to dig deep into the leaf senescense proteome of Glycine max. J Proteom. 148: 65-74.

Gutierrez-Beltran E, Moschou PN, Smertenko AP, Bozhkov OV (2015) Tudor Staphylococcal nuclease links formation of stress granules and processing bodies with mRNA catabolism in Arabidopsis. The Plant Cell. 27: 926-943.

Hahlbrock K, Scheel D (1989) Physiology and molecular biology of phenylpropanoid metabolism. Ann Rev Plant Phys Plant Mol Biol. 40: 347-369.

Huang S, Millar H (2013) Succinate dehydrogenase: the complex roles of a simple enzyme. Curr Opin Plant Biol. 16 344-349.

Jez JM, Noel JP (2002) Reaction mechanism of chalcone isomerase. The J Biol Chem. 277: 1361-1369.

Kedersha N, Chen S, Gilks N, Li W, Miller IJ, Stahl J, Anderson $P$ (2002) Evidence that ternary complex (elF2-GTP-tRNAi ${ }^{\mathrm{Met}}$ ) deficient preinitiation complexes are core constituents of mammalian stress granules. Mol Biol Cell. 13: 195-210.

Kelly G, Sade N, Attia Z, Secchi F, Zwieniecki M, Holbrook NM, Levi A, Alchanatis V, Moshelion M, Granot D (2014) Relationship between hexokinase and the aquaporin PIP1 in the regulation of photosynthesis and plant growth. Plos One. 9: $e 87888$ / www.plosone.org

Kuhn JM, Hugouvieux V, Schroeder JI (2008) mRNA cap binding proteins: effects on abscisic acid signal 
transduction, mRNA processing, and microarray analyses. Curr Topics Microbiol Immun. 326: 139-150.

Lery LMS, Coelho A, Von Kruger WMA, Gonçalves MSM, Santos MF, Valente RH, Santos EO, Rocha SLG, Perales J, Domont GB, Teixeira KRS, Bisch PM (2008) Protein expression profile of Gluconacetobacter diazotrophicus PAL5, a sugarcane endophytic plant growth-promoting bacterium. Proteomic. 8: 1631-1644.

Leyser O (2009) The control of shoot branching: an example of plant information processing. Plant Cell Environ. 32: 694-703.

Li J, Ou-Lee T, Raba R, Amundson RG, Last RL (1993) Arabidopsis flavonoid mutants are hypersensitive to UV-B irradiation. The Plant Cell. 5: 171-179.

Lijuan C, Huiming G, Yi L, Hongmel C (2015) Chalcone synthase EaCHS1 from Eupatorium adenophorum functions in salt stress tolerance in tobacco. Plant Cell Rep. 34: 885-894.

Lim $\mathrm{H}$, Cho M-H, Jeon J-S, Bhoo SH, Know Y-K, Hahn T-R (2009) Altered expression of pyrophosphate: fructose-6phosphate 1-phosphotransferase affects the growth of transgenic Arabidopsis plants. Mol Cells. 27: 641-649.

Maranho RC, Benez MM, Maranho GB, Fernandes VNA, Gonela A, Mangolin CA, Machado MFPS (2017) Extraction of total protein from axillary buds of sugarcane (Saccharum spp.) for proteomics analysis. Sugar Tech. 19: 1-5.

Mcalister-Henn L, Small WC (1997) Molecular genetics of yeast TCA cycle isozymes. Progr Nucl Acid Res Mol Biol. 57: 317-39.

Ming R, Moore PH, Wu KK, D’hont A, Glasmann JC, Tew TL (2006) Sugarcane improvement through breeding and biotechnology. Plant Breed Rev. 27: 15-118.

Ongaro V, Bainbridge K, Williamson L, Leyser O (2008) Interactions between axillary branches of Arabdopsis. Mol Plant. 1: 388-400.

Ortiz-Morea FA, Vicentini R, Silva GFF, Silva EM, Carrer $H$, Rodrigues AP, Nogueira FTS (2013) Global analysis of the sugarcane microtranscriptome revels a unique composition of small RNAs associated with axillary bud outgrowth. J Exp Bot. 64: 2307-2320.

Pacheco CM, Pestana-Calsa MC, Gozzo FC, Nogueira RJMC, Menossi MTC (2013) Differentially delayed root proteome responses to salt stress in sugar cane varieties. J Proteome Res. 12: 5681-5696.

Pereira SC, Maehara L, Machado CMM, Farinas CS (2015) 2 G ethanol from the whole sugarcane lignocellulosic biomass. Biotechn Biofuels. 8: 1-16.

Prado H (2008) Pedologia fácil - aplicações na agricultura, Piracicaba, SP: ESALQ, 145 p.

Ramalingam A, Kudapa H, Pazhamala LT, Weckwerth W, Varshney RK (2015) Proteomics and metabolomics: two emerging areas for legume improvement. Front Plant Sci. 6: 1-21.

Richard S, Lapoint G, Rutledge RG, Séguin A (2000) Induction of chalcone synthase expression in white spruce by wounding and jasmonate. Plant Cell Physiol. 41: 982-987.

Santos F, Diola V (2015) Physiology. sugarcane-agricultural production, bioenergy and ethanol. Academic Press, pp. 13-33.
Scadden ADJ (2007) Inosine-containing dsRNA binds a stressgranule-like complex and downregulates gene expression in trans. Mol Cells. 28: 491-500.

Shevchenko A, Wilm M, Vorm O, Mann M (1996) Mass spectrometric sequencing of proteins from silver-stained polyacrylamide gels. Anal Chem. 68: 850-858.

Shin S-Y, Kim M-H, Kim Y-H, Park H-M, Yoon H-S (2013) Coexpression of monodehydroascorbate reductase and dehydroascorbate reductase from Brassica rapa effectively confers tolerance to freezing-induced oxidative stress. Mol Cells. 36: 304-315.

Stiti N, Missihoun TD, Kotchoni SO, Kirch HH, Bartels D (2011) Aldehyde dehydrogenases in Arabidopsis thaliana: biochemical requirements, metabolic pathways, and functional analysis. Frontiers of Plant Sci. 2: 65.

Sundström JF, Vaculova A, Smertenko AP, Savenkov EI, Golovko A, Minina E, Tiwari BS, Rodrigues-Nieto $S$, Zamyatnin AA, Välineva T, Saarikettu $K$, Frilander MJ, Suarez MF, Zavialov A, Stahl U, Hussey PJ, Silvennoinen O, Sunderberg E, Zhivotovsky B, Bozhkov PV (2009) Tudor staphylococcal nuclease is an evolutionarily conserved component of the programmed cell death degradome. Nature Cell Biol. 11: 1347-1354.

Sunkar R, Bartels D, Kirch HH (2003) Overexpression of a stress-inducible aldehyde dehydrogenase gene from Arabidopsis thaliana in transgenic plants improves stress tolerance. The Plant J. 35: 452-464.

Szklarczyk D, Morris JH, Cook H, Kuhn M, Wyder S, Simonovic M, Santos A, Doncheva NT, Roth A, Bork P, Jensen LJ, Mering Von C (2017) The STRING database in 2017: quality-controlled protein-protein association networks, made broadly accessible. Nucleic Acids Res. 45: D362-D368.

Tovar-Méndez A, Miernyk JA, Randall DD (2003) Regulation of pyruvate dehydrogenase complex activity in plant cells. Eur J Biochem. 270: 1043-1049.

Tuli L, Ressom HW (2009) LC-MS based detection of differential protein expression. J Proteomics Bioinform. 2: 416-438.

Van Dillewijn C (1952) Botany of sugarcane. Chronica Botanica, New York: Stechert-Hafner, 371 p.

Wang C, Washida H, Crofts AJ, Hamada S, Katsube-Tanaka T, Kim D, Choi SB, Modi M, Singh S, Okita TW (2008) The cytoplasmic-localized, cytoskeletal-associated RNA binding protein OsTudor-SN: evidence for an essential role in storage protein RNA transport and localization. Plant J. 55: 443-454.

Wang D, Heckathorn AS, Wang X, Philpott SM (2012) A meta-analysis of plant physiological and growth responses to temperature and elevated $\mathrm{CO}_{2}$. Oecologia. 169: 1-13.

Weissbach R, Scadden ADJ (2012) Tudor-SN and ADAR1 are components of cytoplasmic stress granules. RNA. 18: 462471.

Yan C, Yan Z, Wang Y, Yan X, Han Y (2014) Tudor-SN, a component of stress granules, regulates growth under salt stress by modulating GA200x3 mRNA levels in Arabidopsis. J Exp Bot. 65: 5933-5944.

Zhang JF, Yuan L, Shao Y, Du W, Yan DW, Lu YT (2008) The disturbance of small RNA pathways enhanced abscisic acid response and multiple stress responses in Arabidopsis. Plant Cell Environ. 31: 562-574. 